\title{
Beta-Glucan MM-10-001
}

National Cancer Institute

\section{Source}

National Cancer Institute. Beta-Glucan MM-10-001. NCI Thesaurus. Code C82657.

A powder formulation containing a triple helix beta-glucan, isolated from the cell walls of the shiitake mushroom (Lentinula edodes), with potential immunostimulating activity. The beta-glucan in beta-glucan MM-10-001 binds to a lectin site within the complement receptor 3 (CR3 or iC3b receptor) on leukocytes, priming the receptor to trigger cytotoxic degranulation of leukocytes when leukocyte CR3 binds to iC3b-opsonized tumor cells. iC3b is the proteolyticly inactive product of the complement cleavage fragment C3b. 